https://doi.org/10.15407/ujpe65.7.625

V.O. GUBANOV, A.P. NAUMENKO, I.S. DOTSENKO, M.M. SABOV, D.V. GRYN, L.A. BULAVIN

Taras Shevchenko National University of Kyiv

(64/13, Volodymyrs'ka Str., Kyiv 01601, Ukraine)

\title{
FINE SPIN-DEPENDENT SPLITTING \\ OF ELECTRONIC EXCITATIONS AND THEIR DISPERSION IN SINGLE-LAYER GRAPHENE AND GRAPHITE ${ }^{1}$
}

\section{Introduction}

In work [1], when describing the dispersion of vibrational excitations in single-layer graphene and crystalline graphite without taking the spin of electronic excitations into account, the projective classes and standard factor systems, as well as the single-valued (vector) and projectively equivalent ( $p$-equivalent) irreducible projective representations of spatial symmetry groups, according to which those excitations are classified at the high-symmetry points in the Brillouin zones of the above structures, have been determined for the first time. The compatibility conditions for irreducible projective representations of various projective classes corresponding to an ordering of the

(C) V.O. GUBANOV, A.P. NAUMENKO, I.S. DOTSENKO, M.M. SABOV, D.V. GRYN, L.A. BULAVIN, 2020

ISSN 2071-0194. Ukr. J. Phys. 2020. Vol. 65, No. 7 spatial symmetry groups and the wave-vector groups with $\mathbf{k} \neq 0$ are determined together with the realization of the projective classes that are possible for those groups.

The account for the electron spin for the electronic $\pi$-bands in single-layer graphene and crystalline graphite, which was performed in work cite2, doubles the number of electronic energy states and, as a result, gives rise to their new classification according to the double-valued (spinor) irreducible projective representations in the new system of projective classes. The unambiguity in the ordering of spatial symmetry groups at various high-symmetry points

1 The paper was presented at the XXIVth Galyna Puchkovska International School-Seminar "Spectroscopy of Molecules and Crystals" (August 25-30, 2019, Odesa, Ukraine). 
in the $\mathbf{k}$-space survives at that, but there arises a possibility of the spin-dependent splitting or principal merging of excited electronic energy states, which should manifest itself in the fine structure of electronic excitations in crystalline systems with a low spin-orbit interaction energy, e.g., in carbon structures, where the spin-orbit interaction energy is only 1.0-1.5 meV [3].

The electronic "skeletons", e.g., in hexagonal boron nitride $(h-\mathrm{BN}$ or $\gamma$-BN) and the hexagonal polytypes $2 H_{a}$ and $2 H_{c}$ of the transition-metal dichalcogenides $\left(\mathrm{MoS}_{2}, \mathrm{MoSe}_{2}, \mathrm{WS}_{2}, \mathrm{WSe}_{2}, \mathrm{TeS}_{2}\right.$, and $\mathrm{TeSe}_{2}$ ) are also based on the $s p^{2}$-hybridization of electronic states. The crystal lattice symmetry in those substances is also described by the spatial group $P 6_{3} / m m c\left(D_{6 h}^{4}\right)$ as in crystalline graphite, and the energies of spin-orbit interaction for the corresponding $\pi$-bands are much higher than for carbon $\pi$ bands. Therefore, we decided to consider the qualitative character of the electron spin influence on the structure of electronic $\pi$-bands and the dispersion of $\pi$-electronic states in graphite and other compounds, whose crystal lattices are characterized by this spatial symmetry, in more details.

\section{Symmetry Basics for Determining the Qualitative Character of the Electron Spin Influence on the Structure of the Electronic Excitation Energy Spectra and Their Dispersion in Crystalline Graphite $\gamma-C$ and Single-Layer Graphene $C_{L, 1}$}

Among the electronic excitations at various highsymmetry points in the corresponding Brillouin zones of crystalline graphite $\gamma-C$ and single-layer graphene $C_{L, 1}$, which were analyzed in works $[1,2]$, we will consider only the excitations of electronic $\pi$-bands. Their wave functions are orthogonal to the wave functions of the $s p^{2}$-hybridized bands of $\sigma$-electrons.

When determining the characters of the projective representations $D_{\pi}$, which describe the symmetry of electronic states (without taking the electron spin into account) at the point $D$ of the corresponding Brillouin zone, we used formulas (1)-(18) from work [1]. At the same time, in order to find the characters of the projective representations $D_{\pi}^{\prime}$, which do the same but making allowance for the electron spin, formulas (2)-(8) from work [2] were applied. Whether the projective representations of the wave-vector groups of spatial symmetry groups belong to the $i$-th projective class $K_{i}$ or not was determined by constructing the factor systems $\omega\left(r_{2}, r_{1}\right)$ and reducing them to the standard form with the help of the functions on groups, the coefficients $u(r)$.

In this work, while determining the correspondence between the projective representations $D_{\pi}$ and $D_{\pi}^{\prime}$, which characterize the symmetry of electronic states without taking and taking, respectively, the electron spin into account, the following relation was additionally used for each wave-vector group of the spatial symmetry groups of crystalline graphite and singlelayer graphene:

$D_{\pi}^{\prime}=D_{\pi} \times D_{1 / 2}^{+}$.

Here, $D_{1 / 2}^{+}$is an even two-dimensional (spinor) projective representation of the rotation group for the total electron angular momentum quantum number $j=\frac{1}{2}$. For the rotation at the angle $\phi$, its characters are determined by the formula [2]

$\chi_{j}\left(c_{\phi}\right)=\frac{\sin [(j+1 / 2) \phi]}{\sin (\phi / 2)}$.

In particular, at the points $\Gamma$ in the Brillouin zones of crystalline graphite [the spatial symmetry group $\left.P 6_{3} / m m c\left(D_{6 h}^{4}\right)\right]$ and single-layer graphene [the diperiodic spatial symmetry group $P 6 / \mathrm{mmm}$ ( $D G 80$ ) [4], the group chart of which coincides with the group chart of the three-periodic space symmetry group $P 6 / m m m\left(D_{6 h}^{1}\right)$ ], the point symmetry groups of equivalent directions are identical; these are the groups $6 / \mathrm{mmm}\left(D_{6 h}\right)$, which coincide with the groups of crystalline and macromolecular classes, respectively.

The symmetry of the valence band ( $\pi$-band) of single-layer graphene $C_{L, 1}$ at the center of its Brillouin zone, i.e., at the point $\Gamma$, for electronic states without taking the electron spin into account, is determined by the representation $\Gamma_{3}^{-}\left(A_{3}^{-}\right)$of the point group $6 / \mathrm{mmm}\left(D_{6 h}\right)$ (the highest-energy binding $\pi$ orbital with $\left.\psi_{v}(\mathbf{r})=\frac{1}{\sqrt{2}}\left[\phi_{1}(\mathbf{r})+\phi_{2}(\mathbf{r})\right]\right)$, and the symmetry of the conduction bands $\left(\pi^{*}\right.$-band, the antibinding $\pi^{*}$-orbital with $\psi_{c}(\mathbf{r})=\frac{1}{\sqrt{2}}\left[\phi_{1}(\mathbf{r})-\phi_{2}(\mathbf{r})\right]$ by the representation $\left.\Gamma_{2}^{+}\left(A_{2}^{+}\right)\right)$. Here, $\phi_{1}(\mathbf{r})$ and $\phi_{2}(\mathbf{r})$ are the atomic $\pi$-orbitals of the first and second crystallographically non-equivalent $\mathrm{C}$ atoms that form a unit cell in single-layer graphene. Using the method of linear combination of atomic orbitals (LCAO), it is easy to find that the highest valence band (not taking the electron spin into account) at the point $\Gamma$ 
Table 1. Characters of the single-valued irreducible representations $\left(\Gamma_{2}^{(0)}\right)^{+}\left(\Gamma_{2}^{+}\right)$ and $\left(\Gamma_{3}^{(0)}\right)^{-}\left(\Gamma_{3}^{-}\right)$(the projective class $\left.K_{0}\right)$, the spinor representation $D_{1 / 2}^{+}$(the projective class $\left.K_{1}\right)$, and the products of the projective representations $\left(\Gamma_{2}^{(0)}\right)^{+} \otimes D_{1 / 2}^{+}$ and $\left(\Gamma_{3}^{(0)}\right)^{-} \otimes D_{1 / 2}^{+}\left(\right.$the projective class $\left.K_{1}\right)$ of the $6 / m m m\left(D_{6 h}\right)$

\begin{tabular}{|c|c|c|c|c|c|c|c|c|c|c|c|c|c|c|c|c|c|}
\hline \multirow{2}{*}{$\begin{array}{c}\text { Projec- } \\
\text { tive } \\
\text { class }\end{array}$} & \multirow{2}{*}{$\begin{array}{l}\text { Notation for irreducible } \\
\text { projective representation }\end{array}$} & \multicolumn{16}{|c|}{$6 / m m m\left(D_{6 h}\right)$} \\
\hline & & $e$ & $c_{3}$ & $c_{3}^{2}$ & $3 u_{2}$ & $c_{2}$ & $c_{6}^{5}$ & $c_{6}$ & $3 u_{2}^{\prime}$ & $i$ & $i c_{3}$ & $i c_{3}^{2}$ & $3 i u_{2}$ & $i c_{2}$ & $i c_{6}^{5}$ & $i c_{6}$ & $3 i u_{2}^{\prime}$ \\
\hline \multirow[t]{2}{*}{$K_{0}$} & $\left(\Gamma_{2}^{(0)}\right)^{+} \quad \Gamma_{2}^{+}$ & 1 & 1 & 1 & 1 & -1 & -1 & -1 & -1 & 1 & 1 & 1 & 1 & -1 & -1 & -1 & -1 \\
\hline & $\left(\Gamma_{3}^{(0)}\right)^{-}$ & 1 & 1 & 1 & -1 & 1 & 1 & 1 & -1 & -1 & -1 & -1 & 1 & -1 & -1 & -1 & 1 \\
\hline \multirow[t]{3}{*}{$K_{1}$} & \multirow{3}{*}{$\begin{array}{c}D_{1 / 2}^{+} \\
\left(\Gamma_{2}^{(0)}\right)^{+} \otimes D_{1 / 2}^{+}=\left(\left(\Gamma^{\prime}\right)_{1}^{(1)}\right)^{+} \\
\left(\Gamma_{2}^{+} \otimes D_{1 / 2}^{+}=\Gamma_{7}^{+}\right) \\
\left(\Gamma_{3}^{(0)}\right)^{-} \otimes D_{1 / 2}^{+}=\left(\left(\Gamma^{\prime}\right)_{2}^{(1)}\right)^{-} \\
\left(\Gamma_{3}^{-} \otimes D_{1 / 2}^{+}=\Gamma_{8}^{-}\right)\end{array}$} & 2 & 1 & -1 & 0 & 0 & $-\sqrt{3}$ & $\sqrt{3}$ & 0 & 2 & 1 & -1 & 0 & 0 & $-\sqrt{3}$ & $\sqrt{3}$ & 0 \\
\hline & & 2 & 1 & -1 & 0 & 0 & $\sqrt{3}$ & $-\sqrt{3}$ & 0 & 2 & 1 & -1 & 0 & 0 & $\sqrt{3}$ & $-\sqrt{3}$ & 0 \\
\hline & & 2 & 1 & -1 & 0 & 0 & $-\sqrt{3}$ & $\sqrt{3}$ & 0 & -2 & -1 & 1 & 0 & 0 & $\sqrt{3}$ & $-\sqrt{3}$ & 0 \\
\hline
\end{tabular}

in crystalline graphite $\gamma-C$, as well as in single-layer graphene $C_{L, 1}$, has the $\Gamma_{3}^{-}\left(A_{3}^{-}\right)$symmetry, and the lower-energy $\pi$-band has the $\Gamma_{2}^{+}\left(A_{2}^{+}\right)$symmetry. The lower-energy conduction $\pi^{*}$-band (not taking the electron spin into account) in crystalline graphite, as in single-layer graphene, has the $\Gamma_{2}^{+}\left(A_{2}^{+}\right)$symmetry, and the higher-energy conduction $\pi^{*}$-band has the $\Gamma_{3}^{-}\left(A_{3}^{-}\right)$symmetry.

From Table 1 of this work, as well as Table 4 of work [1] and Table 1 of work [2], one can see that if the electron spin is taken into account, the spinless orbital $\Gamma_{2}^{+}$of the projective class $K_{0}$ [in our notation, this is $\left.\left(\Gamma_{2}^{(0)}\right)^{+}\right]$transforms into the spin (spinor) orbital $\Gamma_{7}^{+}$of the projective class $K_{1}$ [in our notation, this is $\left.\left(\left(\Gamma^{\prime}\right)_{1}^{(1)}\right)^{+}\right]$, and the spinless orbital $\Gamma_{3}^{-}$of the projective class $K_{0}$ [in our notation, this is $\left(\Gamma_{3}^{(0)}\right)^{-}$] into the spin (spinor) orbital $\Gamma_{8}^{-}$of the projective class $K_{1}$ [in our notation, this is $\left(\left(\Gamma^{\prime}\right)_{2}^{(1)}\right)^{-}$] in both single-layer graphene and crystalline graphite.

Let us first find the compatibility condition for the irreducible projective representations of electronic excitations along the line $\Gamma-\Delta-A$ in the Brillouin zone of crystalline graphite [1] both neglecting the electron spin and taking it into account.

\subsection{Point $\Delta$}

The factor group of the wave-vector group by an infinite invariant subgroup of translations at the point $\Delta$ of the Brillouin zone in crystalline graphite $\gamma-C$ is isomorphic to the point group $6 \mathrm{~mm}\left(C_{6 v}\right)$, which is a symmetry group of equivalent directions at this point. The wave-vector star at the point $\Delta$ contains two rays; these are two vectors directed along the axis $\mathbf{k}_{z}:\left(\mathbf{k}_{\Delta}\right)_{1}=-\mathbf{k}_{z}$ and $\left(\mathbf{k}_{\Delta}\right)_{2}=\mathbf{k}_{z}\left(0<\left|\mathbf{k}_{z}\right|<\frac{1}{2}\left|\mathbf{b}_{1}\right|\right)$.

It is easy to see that, for the factor system $\omega_{1, \Delta}\left(r_{2}, r_{1}\right)$, which is determined by the symmetry properties of the crystal spatial group, all values calculated by formula (8) of work [1] are equal to +1 . This means that $\omega_{1, \Delta}\left(r_{2}, r_{1}\right)=\omega_{(0)}^{\prime}\left(r_{2}, r_{1}\right)$, i.e., the factor system $\omega_{1, \Delta}\left(r_{2}, r_{1}\right)$ is a standard factor system of the projective class $K_{0}$, and all singlevalued representations of the group $6 \mathrm{~mm}\left(C_{6 v}\right)$ coincide with the vector ones at the point $\Delta$. The transformations of the spinors, the wave functions of the states with a half-integer spin, are characterized by double-valued representations, which have to be projective representations of the ordinary symmetry group [1]. The structure of double-valued representations is determined by the factor systems $\omega_{2}\left(r_{2}, r_{1}\right)$ that reflect the symmetry transformations of spinors or, more precisely, describe the transformations of their spin variables.

The procedure of constructing the factor system $\omega_{2}\left(r_{2}, r_{1}\right)$ and the method of its reduction to the standard form $\omega_{2}^{\prime}\left(r_{2}, r_{1}\right)$ were described in Section 5 of work [1] in detail. The factor system $\omega_{2}\left(r_{2}, r_{1}\right)$ that was constructed following this method for the point 
Table 2. Factor systems $\omega_{2}\left(r_{2}, r_{1}\right)$ at the point $\Delta$ of crystalline graphite [the spatial symmetry group $P 6_{3} / m m c\left(D_{6 h}^{4}\right)$, the point symmetry group $\left.6 m m\left(C_{6 v}\right)\right](a)$ and standard factor system $\omega_{2}^{\prime}\left(r_{2}, r_{1}\right)$ corresponding to the standard form of the factor system $\omega_{2}\left(r_{2}, r_{1}\right)(b)$

\begin{tabular}{|c|c|c|c|c|c|c|c|c|c|c|c|c|c|c|}
\hline \multirow{3}{*}{\multicolumn{2}{|c|}{$\omega_{2}\left(r_{2}, r_{1}\right)$}} & \multirow{3}{*}{$r_{1}$} & \multirow{3}{*}{$\begin{array}{l}1 \\
e\end{array}$} & \multirow{3}{*}{$\begin{array}{l}2 \\
c_{3} \\
\end{array}$} & \multirow{3}{*}{$\begin{array}{c}3 \\
c_{3}^{2}\end{array}$} & \multirow{3}{*}{\multicolumn{2}{|c|}{$\begin{array}{cc}\left(\sigma_{v}\right)_{1} & \left(\sigma_{v}\right)_{2} \\
4 & 5 \\
i\left(u_{2}\right)_{1} & i\left(u_{2}\right)_{2}\end{array}$}} & \multirow{3}{*}{$\begin{array}{c}\left(\sigma_{v}\right)_{3} \\
6 \\
i\left(u_{2}\right)_{3}\end{array}$} & \multirow{3}{*}{$\begin{array}{l}7 \\
c_{2}\end{array}$} & \multirow{3}{*}{$\begin{array}{c}8 \\
c_{6}^{5}\end{array}$} & \multirow{3}{*}{$\begin{array}{l}9 \\
c_{6} \\
\end{array}$} & \multirow{3}{*}{\multicolumn{2}{|c|}{$\begin{array}{cc}\left(\sigma_{v}^{\prime}\right)_{1} & \left(\sigma_{v}^{\prime}\right)_{2} \\
10 & 11 \\
i\left(u_{2}^{\prime}\right)_{1} & i\left(u_{2}^{\prime}\right)_{2}\end{array}$}} & \multirow{3}{*}{$\begin{array}{c}12 \\
i\left(u_{2}^{\prime}\right)_{3}\end{array}$} \\
\hline & & & & & & & & & & & & & & \\
\hline & & & & & & & & & & & & & & \\
\hline \multirow{9}{*}{$\begin{array}{l}\left(\sigma_{v}\right)_{1} \\
\left(\sigma_{v}\right)_{2} \\
\left(\sigma_{v}\right)_{3}\end{array}$} & 1 & $e$ & $1_{(1)}$ & $1_{(2)}$ & $1_{(3)}$ & $1_{(4)}$ & $1_{(5)}$ & $1_{(6)}$ & $1_{(7)}$ & $1_{(8)}$ & $1_{(9)}$ & $1_{(10)}$ & $1_{(11)}$ & $1_{(12)}$ \\
\hline & 2 & $c_{3}$ & $1_{(2)}$ & $1_{(3)}$ & $-1_{(1)}$ & $-1_{(6)}$ & $-1_{(4)}$ & $-1_{(5)}$ & $1_{(8)}$ & $-1_{(9)}$ & $1_{(7)}$ & $-1_{(12)}$ & $-1_{(10)}$ & $-1_{(11)}$ \\
\hline & 3 & $c_{3}^{2}$ & $1_{(3)}$ & $-1_{(1)}$ & $-1_{(2)}$ & $1_{(5)}$ & $1_{(6)}$ & $1_{(4)}$ & $-1_{(9)}$ & $-1_{(7)}$ & $1_{(8)}$ & $1_{(11)}$ & $1_{(12)}$ & $1_{(10)}$ \\
\hline & 4 & $i\left(u_{2}\right)_{1}$ & $1_{(4)}$ & $-1_{(5)}$ & $1_{(6)}$ & $-1_{(1)}$ & $1_{(2)}$ & $-1_{(3)}$ & $-1_{(10)}$ & $1_{(11)}$ & $1_{(12)}$ & $1_{(7)}$ & $-1_{(8)}$ & $-1_{(9)}$ \\
\hline & 5 & $i\left(u_{2}\right)_{2}$ & $1_{(5)}$ & $-1_{(6)}$ & $1_{(4)}$ & $-1_{(3)}$ & $-1_{(1)}$ & $1_{(2)}$ & $-1_{(11)}$ & $1_{(12)}$ & $1_{(10)}$ & $-1_{(9)}$ & $1_{(7)}$ & $-1_{(8)}$ \\
\hline & 6 & $i\left(u_{2}\right)_{3}$ & $1_{(6)}$ & $-1_{(4)}$ & $1_{(5)}$ & $1_{(2)}$ & $-1_{(3)}$ & $-1_{(1)}$ & $-1_{(12)}$ & $1_{(10)}$ & $1_{(11)}$ & $-1_{(8)}$ & $-1_{(9)}$ & $1_{(7)}$ \\
\hline & 7 & $c_{2}$ & $1_{(7)}$ & $1_{(8)}$ & $-1_{(9)}$ & $1_{(10)}$ & $1_{(11)}$ & $1_{(12)}$ & $-1_{(1)}$ & $-1_{(2)}$ & $1_{(3)}$ & $-1_{(4)}$ & $-1_{(5)}$ & $-1_{(6)}$ \\
\hline & 8 & $c_{6}^{5}$ & $1_{(8)}$ & $-1_{(9)}$ & $-1_{(7)}$ & $-1_{(12)}$ & $-1_{(10)}$ & $-1_{(11)}$ & $-1_{(2)}$ & $-1_{(3)}$ & $-1_{(1)}$ & $1_{(6)}$ & $1_{(4)}$ & $1_{(5)}$ \\
\hline & 9 & $c_{6}$ & $1_{(9)}$ & $1_{(7)}$ & $1_{(8)}$ & $-1_{(11)}$ & $-1_{(12)}$ & $-1_{(10)}$ & $1_{(3)}$ & $-1_{(1)}$ & $1_{(2)}$ & $1_{(5)}$ & $1_{(6)}$ & $1_{(4)}$ \\
\hline \multirow{4}{*}{$\begin{array}{l}\left(\sigma_{v}^{\prime}\right)_{1} \\
\left(\sigma_{v}^{\prime}\right)_{2} \\
\left(\sigma_{v}^{\prime}\right)_{3}\end{array}$} & 10 & $i\left(u_{2}^{\prime}\right)_{1}$ & $1_{(10)}$ & $-1_{(11)}$ & $1_{(12)}$ & $-1_{(7)}$ & $1_{(8)}$ & $1_{(9)}$ & $1_{(4)}$ & $-1_{(5)}$ & $-1_{(6)}$ & $-1_{(1)}$ & $1_{(2)}$ & $-1_{(3)}$ \\
\hline & 11 & $i\left(u_{2}^{\prime}\right)_{2}$ & $1_{(11)}$ & $-1_{(12)}$ & $1_{(10)}$ & $1_{(9)}$ & $-1_{(7)}$ & $1_{(8)}$ & $1_{(5)}$ & $-1_{(6)}$ & $-1_{(4)}$ & $-1_{(3)}$ & $-1_{(1)}$ & $1_{(2)}$ \\
\hline & 12 & $i\left(u_{2}^{\prime}\right)_{3}$ & $1_{(12)}$ & $-1_{(10)}$ & $1_{(11)}$ & $1_{(8)}$ & $1_{(9)}$ & $-1_{(7)}$ & $1_{(6)}$ & $-1_{(4)}$ & $-1_{(5)}$ & $1_{(2)}$ & $-1_{(3)}$ & $-1_{(1)}$ \\
\hline & & $u_{2}(r)$ & 1 & -1 & 1 & $i$ & $i$ & $i$ & $i$ & $-i$ & $-i$ & -1 & -1 & -1 \\
\hline
\end{tabular}

\begin{tabular}{|c|c|c|c|c|c|c|c|c|c|c|c|c|c|c|c|}
\hline \multirow{2}{*}{\multicolumn{3}{|c|}{$\begin{array}{l}\omega_{2}^{\prime}\left(r_{2}, r_{1}\right)= \\
=\omega_{(1)}^{\prime}\left(r_{2}, r_{1}\right)\end{array}$}} & \multirow{3}{*}{$r_{1}$} & \multicolumn{6}{|c|}{$a$} & \multicolumn{6}{|c|}{$b$} \\
\hline & & & & \multirow{2}{*}{ e } & \multirow{2}{*}{$\begin{array}{c}2 \\
c_{3}\end{array}$} & \multirow{2}{*}{$\begin{array}{l}3 \\
c_{3}^{2}\end{array}$} & \multirow{2}{*}{$i\left(u_{2}\right)_{1}$} & \multirow{2}{*}{$i\left(u_{2}\right)_{2}$} & \multirow{2}{*}{$i\left(u_{2}\right)_{3}$} & \multirow{2}{*}{$\begin{array}{c}7 \\
c_{2}\end{array}$} & \multirow{2}{*}{$c_{6}^{5}$} & \multirow{2}{*}{$\begin{array}{l}9 \\
c_{6}\end{array}$} & \multirow{2}{*}{$i\left(u_{2}^{\prime}\right)_{1}$} & \multirow{2}{*}{$i\left(u_{2}^{\prime}\right)_{2}$} & \multirow{2}{*}{$\begin{array}{c}12 \\
i\left(u_{2}^{\prime}\right)_{3}\end{array}$} \\
\hline & & & & & & & & & & & & & & & \\
\hline \multirow{6}{*}{$a$} & & 1 & $e$ & $1_{(1)}$ & $1_{(2)}$ & $1_{(3)}$ & $1_{(4)}$ & $1_{(5)}$ & $1_{(6)}$ & $1_{(7)}$ & $1_{(8)}$ & $1_{(9)}$ & $1_{(10)}$ & $1_{(11)}$ & $1_{(12)}$ \\
\hline & $a_{1}$ & 2 & $c_{3}$ & $1_{(2)}$ & $1_{(3)}$ & $1_{(1)}$ & $1_{(6)}$ & $1_{(4)}$ & $1_{(5)}$ & $1_{(8)}$ & $1_{(9)}$ & $1_{(7)}$ & $1_{(12)}$ & $1_{(10)}$ & $1_{(11)}$ \\
\hline & & 3 & $c_{3}^{2}$ & $1_{(3)}$ & $1_{(1)}$ & $1_{(2)}$ & $1_{(5)}$ & $1_{(6)}$ & $1_{(4)}$ & $1_{(9)}$ & $1_{(7)}$ & $1_{(8)}$ & $1_{(11)}$ & $1_{(12)}$ & $1_{(10)}$ \\
\hline & & & $i\left(u_{2}\right)_{1}$ & $1_{(4)}$ & $1_{(5)}$ & $1_{(6)}$ & $1_{(1)}$ & $1_{(2)}$ & $1_{(3)}$ & $-1_{(10)}$ & $-1_{(11)}$ & $-1_{(12)}$ & $-1_{(7)}$ & $-1_{(8)}$ & $-1_{(9)}$ \\
\hline & $a_{2}$ & 5 & $i\left(u_{2}\right)_{3}$ & $1_{(5)}$ & $1_{(6)}$ & $1_{(4)}$ & $1_{(3)}$ & $1_{(1)}$ & $1_{(2)}$ & $-1_{(11)}$ & $-1_{(12)}$ & $-1_{(10)}$ & $-1_{(9)}$ & $-1_{(7)}$ & $-1_{(8)}$ \\
\hline & & 6 & $i\left(u_{2}\right)_{3}$ & $1_{(6)}$ & $1_{(4)}$ & $1_{(5)}$ & $1_{(2)}$ & $1_{(3)}$ & $1_{(1)}$ & $-1_{(12)}$ & $-1_{(10)}$ & $-1_{(11)}$ & $-1_{(8)}$ & $-1_{(9)}$ & $-1_{(7)}$ \\
\hline \multirow{6}{*}{$b$} & & 7 & $c_{2}$ & $1_{(7)}$ & $1_{(8)}$ & $1_{(9)}$ & $1_{(10)}$ & $1_{(11)}$ & $1_{(12)}$ & $1_{(1)}$ & $1_{(2)}$ & $1_{(3)}$ & $1_{(4)}$ & $1_{(5)}$ & $1_{(6)}$ \\
\hline & $b_{1}$ & 8 & $c_{6}^{5}$ & $1_{(8)}$ & $1_{(9)}$ & $1_{(7)}$ & $1_{(12)}$ & $1_{(10)}$ & $1_{(11)}$ & $1_{(2)}$ & $1_{(3)}$ & $1_{(1)}$ & $1_{(6)}$ & $1_{(4)}$ & $1_{(5)}$ \\
\hline & & 9 & $c_{6}$ & $1_{(9)}$ & $1_{(7)}$ & $1_{(8)}$ & $1_{(11)}$ & $1_{(12)}$ & $1_{(10)}$ & $1_{(3)}$ & $1_{(1)}$ & $1_{(2)}$ & $1_{(5)}$ & $1_{(6)}$ & $1_{(4)}$ \\
\hline & & & $i\left(u_{2}^{\prime}\right)_{1}$ & $1_{(10)}$ & $1_{(11)}$ & $1_{(12)}$ & $1_{(7)}$ & $1_{(8)}$ & $1_{(9)}$ & $-1_{(4)}$ & $-1_{(5)}$ & $-1_{(6)}$ & $-1_{(1)}$ & $-1_{(2)}$ & $-1_{(3)}$ \\
\hline & $b_{2}$ & & $i\left(u_{2}^{\prime}\right)_{2}$ & $1_{(11)}$ & $1_{(12)}$ & $1_{(10)}$ & $1_{(9)}$ & $1_{(7)}$ & $1_{(8)}$ & $-1_{(5)}$ & $-1_{(6)}$ & $-1_{(4)}$ & $-1_{(3)}$ & $-1_{(1)}$ & $-1_{(2)}$ \\
\hline & & & $i\left(u_{2}^{\prime}\right)_{3}$ & $1_{(12)}$ & $1_{(10)}$ & $1_{(11)}$ & $1_{(8)}$ & $1_{(9)}$ & $1_{(7)}$ & $-1_{(6)}$ & $-1_{(4)}$ & $-1_{(5)}$ & $-1_{(2)}$ & $-1_{(3)}$ & $-1_{(1)}$ \\
\hline
\end{tabular}


Table 3. Characters of irreducible representations of the double group $(6 \mathrm{~mm})^{\prime}\left(\mathrm{C}_{6 v}^{\prime}\right)$

\begin{tabular}{|c|c|c|c|c|c|c|c|c|c|c|}
\hline \multicolumn{2}{|c|}{$(6 m m)^{\prime}\left(C_{6 v}^{\prime}\right)$} & $e$ & $q$ & $\begin{array}{l}c_{3} \\
q c_{3}^{2}\end{array}$ & $\begin{array}{l}c_{3}^{2}, \\
q c_{3}\end{array}$ & $\begin{array}{l}3 i u_{2} \\
3 q i u_{2}\end{array}$ & $\begin{array}{l}c_{2} \\
q c_{2}\end{array}$ & $\begin{array}{l}c_{6}^{5}, \\
q c_{6}\end{array}$ & $\begin{array}{l}c_{6}, \\
q c_{6}^{5}\end{array}$ & $\begin{array}{l}3 i u_{2}^{\prime}, \\
3 q i u_{2}^{\prime}\end{array}$ \\
\hline$\Gamma_{1}$ & $A_{1}$ & 1 & 1 & 1 & 1 & 1 & 1 & 1 & 1 & 1 \\
\hline$\Gamma_{2}$ & $A_{2}$ & 1 & 1 & 1 & 1 & 1 & -1 & -1 & -1 & -1 \\
\hline$\Gamma_{3}$ & $A_{3}$ & 1 & 1 & 1 & 1 & -1 & 1 & 1 & 1 & -1 \\
\hline$\Gamma_{4}$ & $A_{4}$ & 1 & 1 & 1 & 1 & -1 & -1 & -1 & -1 & 1 \\
\hline$\Gamma_{5}$ & $E_{1}$ & 2 & 2 & -1 & -1 & 0 & 2 & -1 & -1 & 0 \\
\hline$\Gamma_{6}$ & $E_{2}$ & 2 & 2 & -1 & -1 & 0 & -2 & 1 & 1 & 0 \\
\hline$\Gamma_{7}$ & $E_{1}^{\prime}$ & 2 & -2 & 1 & -1 & 0 & 0 & $\sqrt{3}$ & $-\sqrt{3}$ & 0 \\
\hline$\Gamma_{8}$ & $E_{2}^{\prime}$ & 2 & -2 & 1 & -1 & 0 & 0 & $\sqrt{3}$ & $-\sqrt{3}$ & 0 \\
\hline$\Gamma_{9}$ & $E_{3}^{\prime}$ & 2 & -2 & -2 & 2 & 0 & 0 & 0 & 0 & 0 \\
\hline
\end{tabular}

Table 4. Characters of single- and double-valued irreducible representations at the point $\Delta$

\begin{tabular}{|c|c|c|c|c|c|c|c|c|c|c|}
\hline \multirow{2}{*}{$\begin{array}{l}\text { Projec- } \\
\text { tive } \\
\text { class }\end{array}$} & \multirow{2}{*}{\multicolumn{2}{|c|}{$\begin{array}{l}\text { Notation for irreducible } \\
\text { projective } \\
\text { representation }\end{array}$}} & \multicolumn{8}{|c|}{$6 m m\left(C_{6 v}\right)$} \\
\hline & & & $e$ & $c_{3}$ & $c_{3}^{2}$ & $3 i u_{2}$ & $c_{2}$ & $c_{6}^{5}$ & $c_{6}$ & $3 i u_{2}^{\prime}$ \\
\hline \multirow[t]{6}{*}{$K_{0}$} & $\Delta_{1}^{(0)}$ & $\Delta_{1}$ & 1 & 1 & 1 & 1 & $\eta_{\mathbf{k}}$ & $\eta_{\mathbf{k}}$ & $\eta_{\mathbf{k}}$ & $\eta_{\mathbf{k}}$ \\
\hline & $\Delta_{2}^{(0)}$ & $\Delta_{2}$ & 1 & 1 & 1 & -1 & $\eta_{\mathbf{k}}$ & $\eta_{\mathbf{k}}$ & $\eta_{\mathbf{k}}$ & $-\eta_{\mathbf{k}}$ \\
\hline & $\Delta_{3}^{(0)}$ & $\Delta_{3}$ & 1 & 1 & 1 & -1 & $-\eta_{\mathbf{k}}$ & $-\eta_{\mathbf{k}}$ & $-\eta_{\mathbf{k}}$ & $\eta_{\mathbf{k}}$ \\
\hline & $\Delta_{4}^{(0)}$ & $\Delta_{4}$ & 1 & 1 & 1 & 1 & $-\eta_{\mathbf{k}}$ & $-\eta_{\mathbf{k}}$ & $-\eta_{\mathbf{k}}$ & $-\eta_{\mathbf{k}}$ \\
\hline & $\Delta_{5}^{(0)}$ & $\Delta_{5}$ & 2 & -1 & -1 & 0 & $2 \eta_{\mathbf{k}}$ & $-\eta_{\mathbf{k}}$ & $-\eta_{\mathbf{k}}$ & 0 \\
\hline & $\Delta_{6}^{(0)}$ & $\Delta_{6}$ & 2 & -1 & -1 & 0 & $-2 \eta_{\mathbf{k}}$ & $\eta_{\mathbf{k}}$ & $\eta_{\mathbf{k}}$ & 0 \\
\hline \multirow[t]{3}{*}{$K_{1}$} & $\left(\Delta^{\prime}\right)_{1}^{(1)}$ & $\Delta_{7}\left(E_{1}^{\prime}\right)$ & 2 & 1 & -1 & 0 & 0 & $\sqrt{3} \eta_{\mathbf{k}}$ & $-\sqrt{3} \eta_{\mathbf{k}}$ & 0 \\
\hline & $\left(\Delta^{\prime}\right)_{2}^{(1)}$ & $\Delta_{8}\left(E_{2}^{\prime}\right)$ & 2 & 1 & -1 & 0 & 0 & $-\sqrt{3} \eta_{\mathbf{k}}$ & $\sqrt{3} \eta_{\mathbf{k}}$ & 0 \\
\hline & $\left(\Delta^{\prime}\right)_{3}^{(1)}$ & $\Delta_{9}\left(E_{3}^{\prime}\right)$ & 2 & -2 & 2 & 0 & 0 & 0 & 0 & 0 \\
\hline
\end{tabular}

$\eta_{\mathbf{k}}=e^{-\mathbf{k a}_{1} / 2}=e^{-i\left(\mathbf{k}_{\Delta}\right)_{1} \mathbf{a}_{1} / 2}=e^{-i\left(-\mathbf{k}_{z}\right) \mathbf{a}_{1} / 2}$.

group $6 m m\left(C_{6 v}\right)$ is given in Table 2, $a$. While constructing this factor system, the generating elements $a=c_{3}, b=i\left(u_{2}\right)_{1}$, and $c=c_{2}$ were chosen, which satisfy the following generating relations for the doublevalued group $(6 m m)^{\prime}\left(C_{6 v}^{\prime}\right): a^{6}=e, b^{4}=e, c^{4}=e$, $a b=q b a^{2}, a c=c a$, and $b c=q c b$. This factor system, being reduced to the standard form, i.e., the factor system $\omega_{2}^{\prime}\left(r_{2}, r_{1}\right)$, is given in Table $2, b$. The lower part of Table 2, a contains the values of the coefficients $u_{2}(r)$, which are used to reduce the factor system $\omega_{2}\left(r_{2}, r_{1}\right)$ of the point group $6 \mathrm{~mm}\left(C_{6 v}\right)$ to its standard form $\omega_{2}^{\prime}\left(r_{2}, r_{1}\right)$.

In Table 3 , the irreducible representations of the double-valued group $(6 \mathrm{~mm})^{\prime}\left(C_{6 v}^{\prime}\right)$ are presented. The representations that are additional to the irreducible representations of the ordinary group
$6 \mathrm{~mm}\left(C_{6 v}\right)$ are projective for the latter and belong to the projective class $K_{1}$. This fact proves that the factor system $\omega_{2}^{\prime}\left(r_{2}, r_{1}\right)$ is really a standard factor system of the projective class $K_{1}$ of the group $6 m m\left(C_{6 v}\right)$, i.e., $\omega_{2}^{\prime}\left(r_{2}, r_{1}\right)=\omega_{(1)}^{\prime}\left(r_{2}, r_{1}\right)$, where the notation of the standard factor system contains the subscript, where the parenthesized number designates its projective class. In Table $2, b$, the symmetry elements of the group $6 \mathrm{~mm}\left(C_{6 v}\right)$ are additionally grouped horizontally into blocks $a$ and $b$, and vertically into blocks $a\left(a_{1}, a_{2}\right)$ and $b\left(b_{1}, b_{2}\right)$. In Table $2, b$, solid lines are used to distinguish the blocks of the coefficients with a value of -1 .

The characters of irreducible representations of the projective classes $K_{0}$ (ordinary single-valued or vector) and $K_{1}$ (double-valued projective or spinor) at 
the point $\Delta$ are presented in Table 4 . There is no additional degeneracy of states, if their invariance at the point $\Delta$ under the time inversion operation is taken into account.

The compatibility of irreducible projective representations at various points in the Brillouin zone of crystalline structures belonging to a definite spatial symmetry group is established by analyzing the atomic equivalence representations at those points $^{2}$. Let us find the compatibility relations between the projective representations that characterize the symmetry of electronic $\pi$-bands not taking and taking the electron spin into account for crystalline graphite between the points $\Gamma$ and $A$ in its Brillouin zone.

In work [1], it was shown that the standard factor system for the vibrational and electronic states in crystalline graphite $\gamma$ - $C$ [the spatial symmetry group $P 6_{3} / m m c\left(D_{6 h}^{4}\right)$, the point symmetry group of equivalent directions is the crystalline class group $\left.6 / \mathrm{mmm}\left(D_{6 h}\right)\right]$ at the point $A$ of its Brillouin zone without taking the electron spin into account belongs to the projective class $K_{5}$, whereas the standard factor system for the electronic states taking the electron spin into account belongs to the projective class $K_{4}$. This means that the representations of the projective class $K_{0}$ for the electronic states at the point $\Gamma$ without taking the electron spin into account transform into the representations of the projective class $K_{5}$ at the point $A$; and the representations of the projective class $K_{1}$ for the electronic states at the point $\Gamma$ taking the spin into account [1], into the representations of the projective class $K_{4}$ at the point $A$. According to which projective representations the vibrational or electronic states (not taking the spin or taking an integer spin into account) and the electronic states with the half-integer spin (taking the electron spin into account) transform at the point $A$, i.e., the compatibility conditions for the ordinary and projective representations at the point $\Gamma$ and the projective representations at the point $A$, is determined by the atomic equivalence representations at the points $\Gamma$ and $A$.

Table 5 demonstrates the characters of the equivalent group representations at the points $\Gamma$ and $A$ in the Brillouin zone of crystalline graphite $\gamma-C$. The

2 This is true for the orbitals of the same spatial symmetry. point symmetry groups of equivalent directions in them are characterized by the same point group $6 / \mathrm{mmm}\left(D_{6 h}\right)$ (taken from work [1]). It is easy to see that only the elements $e, c_{3}, c_{3}^{2}$, and $3 i u_{2}$ have identical characters of the projective equivalence representations at the points $\Gamma$ and $A$ in the Brillouin zone of crystalline graphite. The symmetry of the electron $\pi$ - and $\pi^{*}$-orbitals without taking the electron spin into account is characterized by one-dimensional representations at the point $\Gamma$ and by two-dimensional projective representations at the point $A$. This means that the valence $\pi$-bands (these are the bands $\Gamma_{3}^{-}$and $\Gamma_{2}^{+}$), which are non-degenerate at the point $\Gamma$, and the conduction $\pi^{*}$-bands (these are also the bands $\Gamma_{3}^{-}$ and $\Gamma_{2}^{+}$), which are non-degenerate at the point $A$, combine in pairs to form doubly degenerate electronic bands, the symmetry of which is characterized by projective representations with the characters determined by the sums of representation characters for elements with identical nonzero characters in the equivalence representations for the points $\Gamma$ and $A$. From Table 5 and taking Table 9 from work [1] into account, one can see that, at the point $\Gamma$, the non-degenerate orbitals of the valence $\pi$-bands (without taking the electron spin into account) $\Gamma_{3}^{-}$and $\Gamma_{2}^{+}$of the projective class $K_{0}$, as well as the non-degenerate orbitals of the conductance $\pi^{*}$-bands $\Gamma_{2}^{+}$and $\Gamma_{3}^{-}$, combine in pairs into double-degenerate orbitals with the symmetry $A_{1}^{(5)}$ of the projective class $K_{5}$.

Table 5 also demonstrates the characters of the projective representations of the doubly degenerate spin (spinor) orbitals (taking the electron spin into account) at the point $\Gamma$; these are the orbitals $\left(\left(\Gamma^{\prime}\right)_{1}^{(1)}\right)^{+} \equiv \Gamma_{7}^{+}$and $\left(\left(\Gamma^{\prime}\right)_{2}^{(1)}\right)^{-} \equiv \Gamma_{8}^{-}$, the symmetry of which is characterized by the projective representations of the projective class $K_{1}$. The standard factor system for the spinor states at the point $A$ is a standard factor system of the projective class $K_{4}$, in which all projective representations are four-dimensional. In other words, the doubly degenerate spinor orbitals indicated above must also combine into fourfold-degenerate ones at the point $A$. Following the procedure described above for finding the characters of projective representations of doubly degenerate orbitals using the equivalence representations at the points $\Gamma$ and $A$, it is easy to find the characters of those fourfolddegenerate orbitals. In Table 5, these are the characters of the four-dimensional spinor projective rep- 
Table 5. Calculation results for the compatibility relations

between electronic states without taking and taking the electron spin

into account at the points $\Gamma$ and $A$ in the Brillouin zone of crystalline graphite $\gamma-C$

\begin{tabular}{|c|c|c|c|c|c|c|c|c|c|c|c|c|c|c|c|c|}
\hline \multirow{2}{*}{$\begin{array}{l}\text { Notation for irreducible } \\
\text { projective } \\
\text { representation }\end{array}$} & \multicolumn{16}{|c|}{$6 / m m m\left(D_{6 h}\right)$} \\
\hline & $e$ & $c_{3}$ & $c_{3}^{2}$ & $3 u_{2}$ & $c_{2}$ & $c_{6}^{5}$ & $c_{6}$ & $3 u_{2}^{\prime}$ & $i$ & $i c_{3}$ & $i c_{3}^{2}$ & $3 i u_{2}$ & $i c_{2}$ & $i c_{6}^{5}$ & $i c_{6}$ & $3 i u_{2}^{\prime}$ \\
\hline$\Gamma_{\text {eq }}$ & 4 & 4 & 4 & 0 & 0 & 0 & 0 & 4 & 0 & 0 & 0 & 4 & 4 & 4 & 4 & 0 \\
\hline$A_{\mathrm{eq}}$ & 4 & 4 & 4 & 0 & 0 & 0 & 0 & 0 & 0 & 0 & 0 & 4 & 0 & 0 & 0 & 0 \\
\hline$\Gamma_{2}^{+}$ & 1 & 1 & 1 & 1 & -1 & -1 & -1 & -1 & 1 & 1 & 1 & 1 & -1 & -1 & -1 & -1 \\
\hline$u_{1, A}(r)$ & 1 & 1 & 1 & 1 & 1 & 1 & 1 & 1 & 1 & 1 & 1 & 1 & -1 & -1 & -1 & -1 \\
\hline$u_{1, A}(r) \Gamma_{2}^{+}$ & 1 & 1 & 1 & 1 & -1 & -1 & -1 & -1 & 1 & 1 & 1 & 1 & 1 & 1 & 1 & 1 \\
\hline$\Gamma_{3}^{-}$ & 1 & 1 & 1 & -1 & 1 & 1 & 1 & -1 & -1 & -1 & -1 & 1 & -1 & -1 & -1 & 1 \\
\hline$u_{1, A}(r) \Gamma_{3}^{-}$ & 1 & 1 & 1 & -1 & 1 & 1 & 1 & -1 & -1 & -1 & -1 & 1 & 1 & 1 & 1 & -1 \\
\hline$\left(\Gamma_{2}^{+}+\Gamma_{3}^{-}\right)$ & 2 & 2 & 2 & 0 & 0 & 0 & 0 & -2 & 0 & 0 & 0 & 2 & -2 & -2 & -2 & 0 \\
\hline$u_{1, A}(r)\left(\Gamma_{2}^{+}+\Gamma_{3}^{-}\right)$ & 2 & 2 & 2 & 0 & 0 & 0 & 0 & -2 & 0 & 0 & 0 & 2 & 2 & 2 & 2 & 0 \\
\hline$A_{1}^{(5)}$ & 2 & 2 & 2 & 0 & 0 & 0 & 0 & 0 & 0 & 0 & 0 & 2 & 0 & 0 & 0 & 0 \\
\hline $2 A_{1}^{(5)}$ & 4 & 4 & 4 & 0 & 0 & 0 & 0 & 0 & 0 & 0 & 0 & 4 & 0 & 0 & 0 & 0 \\
\hline$\left(\left(\Gamma^{\prime}\right)_{2}^{(1)}\right)^{+} \quad\left(\Gamma_{7}^{+}\right)$ & 2 & 1 & -1 & 0 & 0 & $\sqrt{3}$ & $-\sqrt{3}$ & 0 & 2 & 1 & -1 & 0 & 0 & $\sqrt{3}$ & $-\sqrt{3}$ & 0 \\
\hline$\left(\left(\Gamma^{\prime}\right)_{3}^{(1)}\right)^{-} \quad\left(\Gamma_{8}^{-}\right)$ & 2 & 1 & -1 & 0 & 0 & $-\sqrt{3}$ & $\sqrt{3}$ & 0 & -2 & -1 & 1 & 0 & 0 & $\sqrt{3}$ & $-\sqrt{3}$ & 0 \\
\hline$\left(\left(\left(\Gamma^{\prime}\right)_{1}^{(1)}\right)^{+}+\left(\left(\Gamma^{\prime}\right)_{2}^{(1)}\right)^{-}\right)$ & 4 & 2 & -2 & 0 & 0 & 0 & 0 & 0 & 0 & 0 & 0 & 0 & 0 & $2 \sqrt{3}$ & $-2 \sqrt{3}$ & 0 \\
\hline$u_{1, A}(r)\left(\left(\left(\Gamma^{\prime}\right)_{1}^{(1)}\right)^{+}+\left(\left(\Gamma^{\prime}\right)_{2}^{(1)}\right)^{-}\right)$ & 4 & 2 & -2 & 0 & 0 & 0 & 0 & 0 & 0 & 0 & 0 & 0 & 0 & $-2 \sqrt{3}$ & $2 \sqrt{3}$ & 0 \\
\hline $2\left(A^{\prime}\right)_{3}^{(4)}$ & 8 & 4 & -4 & 0 & 0 & 0 & 0 & 0 & 0 & 0 & 0 & 0 & 0 & 0 & 0 & 0 \\
\hline
\end{tabular}

resentation $\left(A^{\prime}\right)_{3}^{(4)}$ of the projective class $K_{4}$ (taken from works $[1,2])$.

In a similar way, we can sequentially calculate the compatibility relations for irreducible projective representations: not directly from the point $\Gamma$ to the point $A$ in the Brillouin zone of crystalline graphite $\gamma-C$, but first from the point $\Gamma$ to the intermediate point $\Delta$ and then from the point $\Delta$ to the point $A$. For the corresponding calculation, the character values for the atomic equivalence representations at the point $\Delta-$ these are the representations $\Delta_{\mathrm{eq}}, \Delta_{\mathrm{r}}, \Delta_{\mathrm{vib}}, \Delta_{z}, \Delta_{\pi}, D_{1 / 2}^{+}, \Delta_{z}^{\prime}$ and $\Delta_{\pi}^{\prime}$ - are presented in Table 6 . In addition, a diagram that determines the compatibility of irreducible projective representations of the spatial group $P 6_{3} / m m c\left(D_{6 h}^{4}\right)$ in the direction $\Gamma-A$ in the Brillouin zone corresponding to this group is exhibited in Fig. 1.

Figure 2 schematically illustrates the dispersion of the electronic $\pi$ and $\pi^{*}$ energy bands $(a)$ without taking and $(b)$ taking the electron spin into account in the Brillouin zone of crystalline graphite $\gamma-C$ along the line $\Gamma-\Delta-A$. As one can see from both Fig. 2 and ISSN 2071-0194. Ukr. J. Phys. 2020. Vol. 65, No. 7
Table 6. Calculation results

for the characters of projective representations without taking and taking the electron spin into account at the point $\Delta$ in the Brillouin zone of crystalline graphite $\gamma-C$

\begin{tabular}{|c|r|r|r|r|r|r|r|r|}
\hline $\begin{array}{c}\text { Notation } \\
\text { for irreducible } \\
\text { projective } \\
\text { representation }\end{array}$ & \multicolumn{7}{|c|}{$6 m m\left(C_{6 v}\right)$} \\
\cline { 3 - 8 } & $e$ & $c_{3}$ & $c_{3}^{2}$ & $3 i u_{2}$ & $c_{2}$ & $c_{6}^{5}$ & $c_{6}$ & $3 i u_{2}^{\prime}$ \\
\hline$\Delta_{\text {eq }}$ & 4 & 4 & 4 & 4 & 0 & 0 & 0 & 0 \\
$\Delta_{\mathbf{r}}$ & 3 & 0 & 0 & 1 & -1 & 2 & 2 & 1 \\
$\Delta_{\mathrm{vib}}$ & 12 & 0 & 0 & 4 & 0 & 0 & 0 & 0 \\
$\Delta_{z}$ & 1 & 1 & 1 & 1 & 1 & 1 & 1 & 1 \\
$\Delta_{\pi}$ & 4 & 4 & 4 & 4 & 0 & 0 & 0 & 0 \\
$D_{1 / 2}^{+}$ & 2 & 1 & -1 & 0 & 0 & $-\sqrt{3}$ & $\sqrt{3}$ & 0 \\
$\Delta_{z}^{\prime}$ & 2 & 1 & -1 & 0 & 0 & $-\sqrt{3}$ & $\sqrt{3}$ & 0 \\
$\Delta_{\mathrm{eq}} \otimes \Delta_{z}^{\prime}$ & 8 & 4 & -4 & 0 & 0 & 0 & 0 & 0 \\
$\Delta_{\pi}^{\prime}$ & & & & 0 & & \\
\hline
\end{tabular}

the results of the detailed group-theoretic consideration carried out above, no spin-dependent splitting of electronic excitations is expected to take place in this 

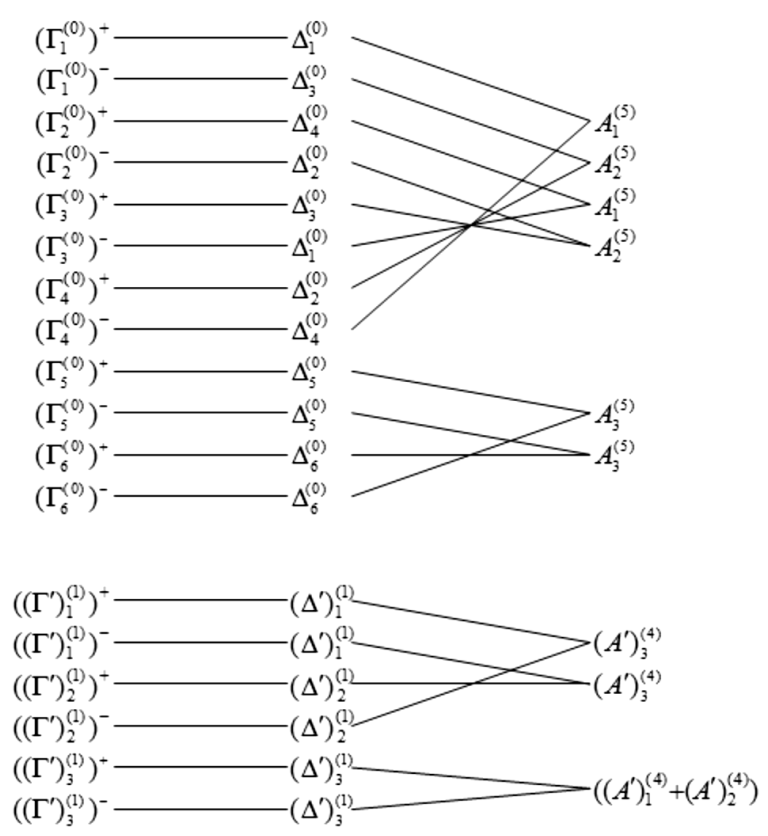

Fig. 1. Compatibility diagram for the irreducible projective representations of the group $P 6_{3} / m m c\left(D_{6 h}^{4}\right)$ in the Brillouin zone of crystalline graphite $\gamma-C$ along the line $\Gamma-\Delta-A$

direction, which is the most symmetric along the $k_{z^{-}}$ axis of the Brillouin zone in crystalline graphite. The account for the electron spin results in that, for every point in the $\Gamma-\Delta-A$ direction, only the degeneracy order of electronic states becomes twice as large, which is admissible for the representations at this point.

Figure 3 exhibits, on the qualitative level, the dispersion of electronic excitations along the line $K-P-H$ in the Brillouin zone of crystalline graphite (a) without taking and (b) taking the electron spin into account (taken from work [2]). The figure demonstrates that, along the $K-P-H$ line in the Brillouin zone of crystalline graphite $\gamma-C$, there are a number of spin-dependent splittings. The origin of their appearance was comprehensively substantiated in work [3] using the group-theoretic methods based on the consideration of the projective representations of spatial symmetry groups. The projective classes of those representations were determined according to their factor systems, which were constructed for the first time. The energies of the spin-dependent splittings are determined by the energy of the spin-orbit interaction, which is low for carbon atoms, being estimated as only 1.0-1.5 meV [3]. Therefore, in order to show the spin-dependent splittings, which are fundamental for the determination of the fine energy structure of electronic states, their energy in the dispersion curves in Fig. 3 was increased $10^{3}$ times.

\subsection{Point $U$}

Figure 4 illustrates the dispersion curves for the electronic excitations along the line $M-U-L$ in the Brillouin zone of crystalline graphite $(a)$ without taking and $(b)$ taking the electron spin into account. The curves were plotted on the basis of the results of quantitative calculations performed in works $[5,6]$.

The compatibility conditions for the irreducible representations at the points $\Gamma$ and $M$ in the Brillouin zones of crystalline graphite and single-layer graphene are trivial. The representations of the orbitals $\left(\Gamma_{2}^{(0)}\right)^{+}\left(\Gamma_{2}^{+}\right)$and $\left(\Gamma_{3}^{(0)}\right)^{-}\left(\Gamma_{3}^{-}\right)$at the points $\Gamma$ in the corresponding Brillouin zones of crystalline graphite and single-layer graphene without taking the electron spin into account transform into the representations $\left(M_{2}^{(0)}\right)^{+}\left(M_{2}^{+}\right)$and $\left(M_{3}^{(0)}\right)^{-}\left(M_{3}^{-}\right)$, respectively, at the points $M$ with the parity conservation; and the representations of the spin $\pi$-orbitals $\left(\left(\Gamma^{\prime}\right)_{1}^{(0)}\right)^{+}\left(\Gamma_{7}^{+}\right)$and $\left(\Gamma^{\prime}\right)_{2}^{-}\left(\Gamma_{8}^{-}\right)$at the points $\Gamma$ transform into the representations of the spin $\pi$-orbitals $\left(\left(M^{\prime}\right)^{(1)}\right)^{+}\left(M_{5}^{+}\right)$and $\left(\left(M^{\prime}\right)^{(1)}\right)^{-}\left(M_{5}^{-}\right)$, respectively, at the points $M$ (taken from work [2]).

At the point $U$ in the Brillouin zone of crystalline graphite $\gamma-C$, the factor group of the wave-vector group for the invariant translation subgroup is isomorphic to the point symmetry group $m m\left(C_{2 v}\right)$. For the point $U$, the latter is a point symmetry group of equivalent directions. The wave-vector star at the point $U$ in the Brillouin zones of crystalline graphite $\gamma-C$ contains six rays: $\left(\mathbf{k}_{U}\right)_{1}=-\mathbf{k}_{z}-\frac{1}{2} \mathbf{b}_{3},\left(\mathbf{k}_{U}\right)_{2}==$ $-\mathbf{k}_{z}+\frac{1}{2} \mathbf{b}_{2},\left(\mathbf{k}_{U}\right)_{3}=-\mathbf{k}_{z}-\frac{1}{2}\left(\mathbf{b}_{2}-\mathbf{b}_{3}\right),\left(\mathbf{k}_{U}\right)_{4}=\mathbf{k}_{z}-$ $-\frac{1}{2} \mathbf{b}_{3},\left(\mathbf{k}_{U}\right)_{5}=\mathbf{k}_{z}+\frac{1}{2} \mathbf{b}_{2}$, and $\left(\mathbf{k}_{U}\right)_{6}=\mathbf{k}_{z}-\frac{1}{2}\left(\mathbf{b}_{2}-\right.$ $-\mathbf{b}_{3}$ ), where $\left.0<\left|\mathbf{k}_{z}\right|<\frac{1}{2}\left|\mathbf{b}_{1}\right|\right)$. As an example, let us consider the ray $\left(\mathbf{k}_{U}\right)_{1}$, i.e., the ray of the point $U_{1}$, for which the symmetry elements transforming this ray into the equivalent one, thus forming a point symmetry group $m m\left(C_{2 v}\right)$, include the elements $e$, $i\left(u_{2}\right)_{1}, c_{2}$, and $i\left(u_{2}^{\prime}\right)_{1}$. As the generating elements of this group, we select the elements $a=i\left(u_{2}\right)_{1}\left(\left(\sigma_{v}\right)_{1}\right)$ and $b=c_{2}$. This choice of generating elements takes the composition principle into account, according to which the group $m m\left(C_{2 v}\right)$ can be represented as the direct group product $m m=m \otimes 2\left(C_{2 v}=C_{s} \otimes C_{2}\right)$.

ISSN 2071-0194. Ukr. J. Phys. 2020. Vol. 65, No. 7 


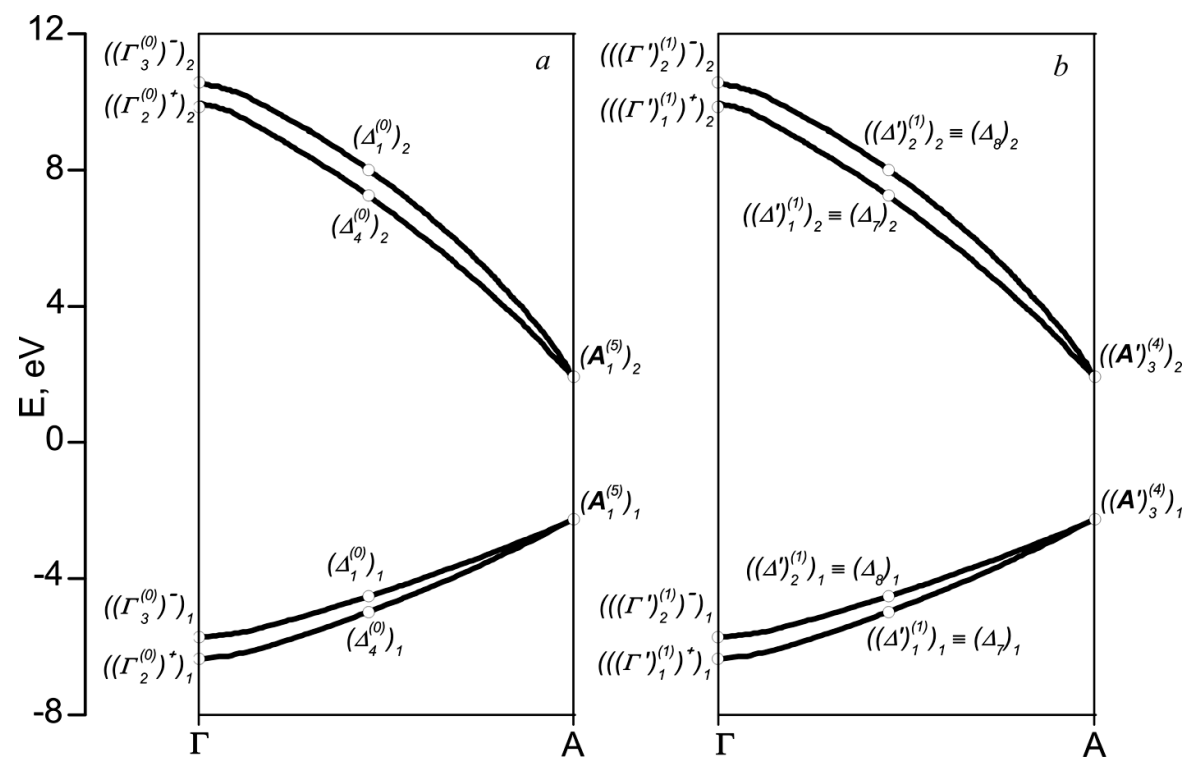

Fig. 2. Dispersion of electronic energy $\pi$ - and $\pi^{*}$-bands in the Brillouin zone of crystalline graphite $\gamma-C$ along the line $\Gamma-\Delta-A$ : without taking $(a)$ and taking the electron spin into account $(b)$

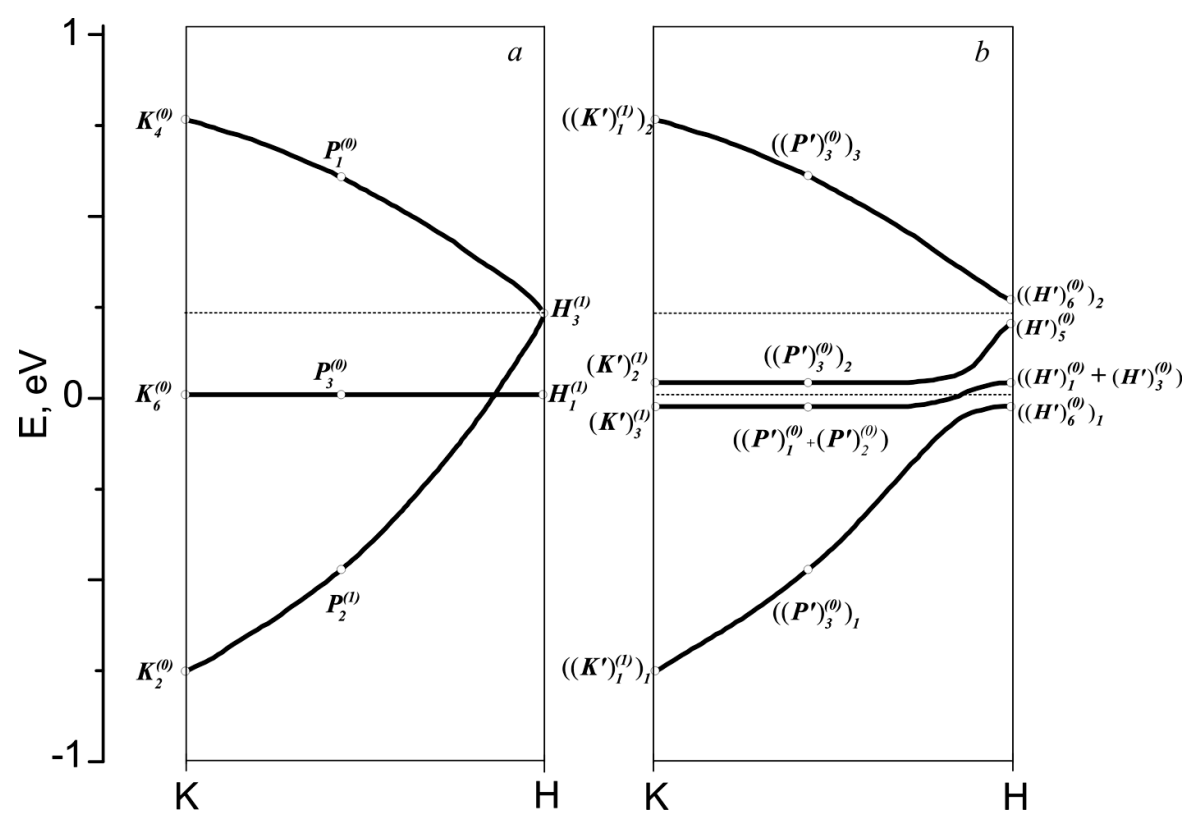

Fig. 3. Dispersion of electronic energy $\pi$ - and $\pi^{*}$-bands in the Brillouin zone of crystalline graphite $\gamma-C$ along the line $K-P-H$ : without taking $(a)$ and taking the electron spin into account $(b)$

Using the defining relations for the group $m m\left(C_{2 v}\right)$, let us calculate all values of the factor system $\omega_{2}\left(r_{2}, r_{1}\right)$. It is clear that, in this case, as the determining relations, we should take those for the double group $(m m)^{\prime}\left(C_{2 v}^{\prime}\right): a^{4}=e, b^{4}=e$, and $a b=q b a$. The corresponding calculation procedure was described in work cite1 in detail. The calculated factor system $\omega_{2}\left(r_{2}, r_{1}\right)$, which describes the transfor- 

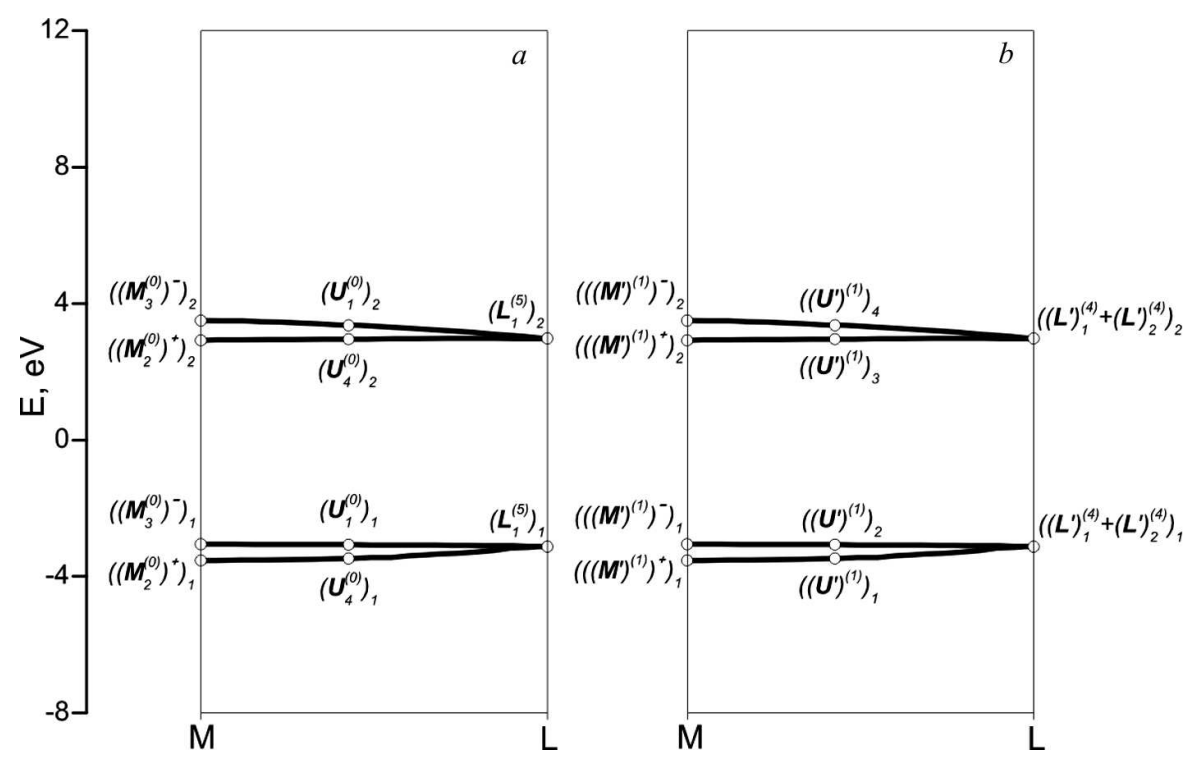

Fig. 4. Dispersion of electronic energy $\pi$ - and $\pi^{*}$-bands in the Brillouin zone of crystalline graphite $\gamma-C$ along the line $M-U-L$ : without taking $(a)$ and taking the electron spin into account $(b)$

Table 7. Factor systems $\omega_{2}\left(r_{2}, r_{1}\right)$ at the point $U$ in crystalline graphite [the spatial symmetry group $P 6_{3} / m m c\left(D_{6 h}^{4}\right)$, the point symmetry group $\left.m m\left(C_{2 v}\right)\right](a)$ and standard factor system $\omega_{2}^{\prime}\left(r_{2}, r_{1}\right)$ corresponding to the standard form of the factor system $\omega_{2}\left(r_{2}, r_{1}\right)(b)$

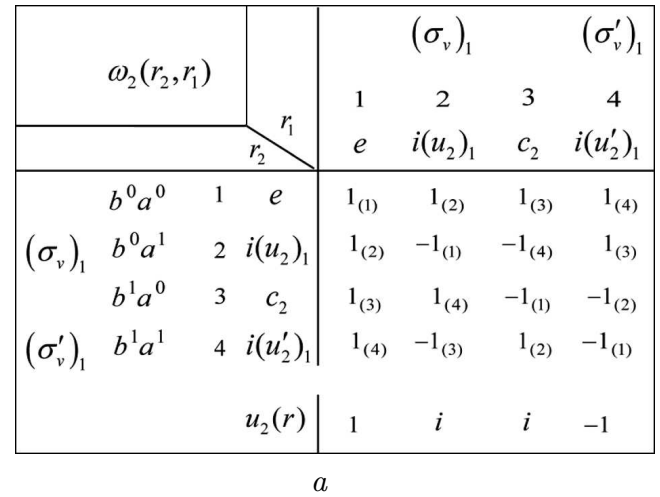

mation of spin variables in the point symmetry group $m m\left(C_{2 v}\right)$, is given in Table $7, a$. This factor system belongs to the projective class $K_{1}$, because $\alpha=-1$, $\beta=1$, and $\gamma=1$ for it. As was done above for analogous factor systems, the subscripts near the coefficient values for the factor system $\omega_{2}\left(r_{2}, r_{1}\right)$ represent a multiplication table of elements of the point symmetry group $m m\left(C_{2 v}\right)$. The numbers in parentheses indicate the numerical designations of elements corresponding to the products $r_{2} r_{1}$.

\section{4}

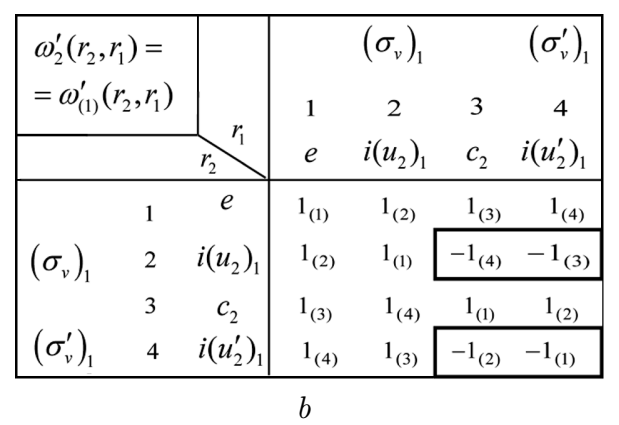

Making use of the coefficients $u_{2}(r)$ presented in the lower part of Table $7, a$, the factor system $\omega_{2}\left(r_{2}, r_{1}\right)$ is reduced to a $p$-equivalent block-symmetric form, the factor system $\omega_{2}^{\prime}\left(r_{2}, r_{1}\right)$, which corresponds to the definition of the standard factor system [1]. This standard factor system of the group $m m\left(C_{2} v\right)$ of the projective class $K_{1}$ is presented in Table $7, b$. It is the values of the coefficients $u_{2}(r)$ that determine the projective spinor representations of symmetry groups. Furthermore, the values of those coefficients

ISSN 2071-0194. Ukr. J. Phys. 2020. Vol. 65, No. 7 
are identical for the same elements $r$ entering various point groups [2].

In Table 8, the characters of irreducible representations of the double group $(m m)^{\prime}\left(C_{2 v}^{\prime}\right)$ are quoted. It is its additional [additional to the vector single-valued representations of the group $\left.m m\left(C_{2 v}\right)\right]$ single-valued representations that are the double-valued (spinor) representations of the group $m m\left(C_{2 v}\right)$. Note that it is the only representation of the projective class $K_{1}$, namely, the representation $\Gamma_{5}\left(E^{\prime}\right)$.

The characters of irreducible representations of a point $U$ of the projective classes $K_{0}$ (the ordinary single-valued or vector ones) and $K_{1}$ (the double-valued projective or spinor one) are given in Table 9 . In work [1], it was shown that the standard factor system for the vibrational and electronic states without taking the electron spin into account for crystalline graphite $\gamma-C$ [the spatial symmetry group $\left.P 6_{3} / m m c\left(D_{6 h}^{4}\right)\right]$ at the point $L$ in its Brillouin zone similarly to the point $A$ - belongs to the projective class $K_{5}$, and the standard factor system for the electronic states taking the electron spin into account again, similarly to the point $A$ - to the projective class $K_{4}$. This means that the representations of the projective class $K_{0}$ for the electronic states without taking the electron spin into account at the point $M$ transform into the representations of the projective class $K_{5}$ at the point $L$, and the representations of the projective class $K_{1}$ for the electronic states taking the electron spin into account at the point $M[1]$ into the representations of the projective class $K_{4}$ at the point $L$. According to which representations at the point $L$ the vibrational or electronic states with an integer spin or neglecting it and the electronic states taking the electron spin into account (the states with a half-integer spin) - in other words, the compatibility conditions for the ordinary and projective representations at the point $M$ and the projective representations at the point $L-$ this issue is again determined by the atomic equivalence representations at the points $M$ and $L$.

Table 10 shows the characteristics of equivalence representations at the points $M$ and $L$ in the Brillouin zone of crystalline graphite $\gamma-C$ (taken from work [1]). At these points, the point symmetry groups of equivalent directions are characterized by the same point groups $m m m\left(D_{2 h}\right)$. From Table 10 , it is easy to see that only the symmetry elements $e$ and $i\left(u_{2}\right)_{1}$ have the same characters of projective equivalence representations at the points $M$ and $L$ in the Brillouin zone of crystalline graphite. The symmetry of the electronic $\pi$ - and $\pi^{*}$-orbitals without taking the electron spin into account is characterized by one-dimensional representations at the point $M$ and two-dimensional projective representations at the point $L$. This means that the electronic valence $\pi$-bands $\left(M_{3}^{(0)}\right)^{-}\left(M_{3}^{-}\right)$and $\left(M_{2}^{(0)}\right)^{+}\left(M_{2}^{+}\right)$ and the electronic conduction $\pi^{*}$-bands $\left(M_{2}^{(0)}\right)^{+}$and $\left(M_{3}^{(0}\right)^{-}$- all are non-degenerate at the point $M-$ combine in pairs at the point $L$ to form doubly degenerate electronic bands. The symmetry of the latter is characterized by projective representations with the characters that are determined, as it was in the case of the points $\Gamma$ and $A$, by the sums of the representation characters for the elements with identical nonzero characters in the equivalence representations at the points $M$ and $L$.

From Table 10 and taking Tables 8 and 9 from work [1] into account, one can also see that the nondegenerate orbitals of the valence $\pi$-bands without taking the electron spin into account at the point $M$

Table 8. Characters of irreducible representations of the double group $(\mathrm{mm})^{\prime}\left(C_{2 v}^{\prime}\right)$

\begin{tabular}{|cc|c|c|c|c|c|}
\hline$(6 / m m)^{\prime}$ & $\left(C_{6 v}^{\prime}\right)$ & $e$ & $q$ & $\begin{array}{l}i\left(u_{2}\right)_{1}, \\
q i\left(u_{2}\right)_{1}\end{array}$ & $\begin{array}{c}c_{2}, \\
q c_{2}\end{array}$ & $\begin{array}{c}i\left(u_{2}^{\prime}\right)_{1}, \\
q i\left(u_{2}^{\prime}\right)_{1}\end{array}$ \\
\hline$\Gamma_{1}$ & $A_{1}$ & 1 & 1 & 1 & 1 & 1 \\
$\Gamma_{2}$ & $A_{2}$ & 1 & 1 & 1 & -1 & -1 \\
$\Gamma_{3}$ & $B_{1}$ & 1 & 1 & -1 & 1 & -1 \\
$\Gamma_{4}$ & $B_{2}$ & 1 & 1 & -1 & -1 & 1 \\
$\Gamma_{5}$ & $E^{\prime}$ & 2 & -2 & 0 & 0 & 0 \\
\hline
\end{tabular}

Table 9. Characters of single- and double-valued irreducible representations at the point $U$

\begin{tabular}{|c|c|c|c|c|c|c|}
\hline \multirow{2}{*}{$\begin{array}{l}\text { Projec- } \\
\text { tive } \\
\text { class }\end{array}$} & \multirow{2}{*}{\multicolumn{2}{|c|}{$\begin{array}{l}\text { Notation } \\
\text { for irreducible } \\
\text { projective } \\
\text { representation }\end{array}$}} & \multicolumn{4}{|c|}{$m m\left(C_{2 v}\right)$} \\
\hline & & & $e$ & $i\left(u_{2}\right)_{1}$ & $c_{2}$ & $i\left(u_{2}^{\prime}\right)_{1}$ \\
\hline \multirow[t]{4}{*}{$K_{0}$} & $U_{1}^{(0)}$ & $U_{1}$ & 1 & 1 & $\eta_{\mathbf{k}}$ & $\eta_{\mathbf{k}}$ \\
\hline & $U_{2}^{(0)}$ & $U_{2}$ & 1 & -1 & $\eta_{\mathbf{k}}$ & $-\eta_{\mathbf{k}}$ \\
\hline & $U_{3}^{(0)}$ & $U_{3}$ & 1 & -1 & $-\eta_{\mathbf{k}}$ & $\eta_{\mathbf{k}}$ \\
\hline & $U_{4}^{(0)}$ & $U_{4}$ & 1 & 1 & $-\eta_{\mathbf{k}}$ & $-\eta_{\mathbf{k}}$ \\
\hline$K_{1}$ & $\left(U^{\prime}\right)^{(1)}$ & $U_{5}\left(E^{\prime}\right)$ & 2 & 0 & 0 & 0 \\
\hline
\end{tabular}

$\eta_{\mathbf{k}}=e^{-i \mathbf{k} \mathbf{a}_{1} / 2}=e^{-i\left(\mathbf{k}_{U}\right)_{1} \mathbf{a}_{1} / 2}=e^{-i\left(-\mathbf{k}_{z}\right) \mathbf{a}_{1} / 2}$. 
Table 10. Calculation results for the compatibility relations between electronic states without taking and taking the electron spin into account at the points $M$ and $L$ in the Brillouin zone of crystalline graphite $\gamma-C$

\begin{tabular}{|c|c|c|c|c|c|c|c|c|}
\hline \multirow{2}{*}{$\begin{array}{l}\text { Notation for irreducible } \\
\text { projective representation }\end{array}$} & \multicolumn{8}{|c|}{$m m m\left(D_{2 h}\right)$} \\
\hline & $e$ & $\left(u_{2}\right)_{1}$ & $c_{2}$ & $\left(u_{2}^{\prime}\right)_{1}$ & $i$ & $i\left(u_{2}\right)_{1}$ & $i c_{2}$ & $i\left(u_{2}^{\prime}\right)_{1}$ \\
\hline$M_{\text {eq }}$ & 4 & 0 & 0 & 4 & 0 & 4 & 4 & 0 \\
\hline$L_{\mathrm{eq}}$ & 4 & 0 & 0 & 0 & 0 & 4 & 0 & 0 \\
\hline$\left(M_{2}^{(0)}\right)^{+} \quad\left(M_{2}^{+}\right)$ & 1 & 1 & -1 & -1 & 1 & 1 & -1 & -1 \\
\hline$\left(M_{3}^{(0)}\right)^{-} \quad\left(M_{3}^{-}\right)$ & 1 & -1 & 1 & -1 & -1 & 1 & -1 & 1 \\
\hline$L_{1}^{(5)}$ & 2 & 0 & 0 & 0 & 0 & 2 & 0 & 0 \\
\hline$D_{1 / 2}^{+}$ & 2 & 0 & 0 & 0 & 2 & 0 & 0 & 0 \\
\hline$\left(\left(M^{\prime}\right)^{(1)}\right)^{+}=\left(M_{2}^{(0)}\right)^{+} \otimes D_{1 / 2}^{+}$ & 2 & 0 & 0 & 0 & 2 & 0 & 0 & 0 \\
\hline$\left(\left(M^{\prime}\right)^{(1)}\right)^{-}=\left(M_{3}^{(0)}\right)^{-} \otimes D_{1 / 2}^{+}$ & 2 & 0 & 0 & 0 & -2 & 0 & 0 & 0 \\
\hline$P_{1}^{(4)}$ & 2 & 2 & 0 & 0 & 0 & 0 & 0 & 0 \\
\hline$P_{2}^{(4)}$ & 2 & -2 & 0 & 0 & 0 & 0 & 0 & 0 \\
\hline$\left(L^{\prime}\right)_{1}^{(4)}$ & 2 & $2 i$ & 0 & 0 & 0 & 0 & 0 & 0 \\
\hline$\left(L^{\prime}\right)_{2}^{(4)}$ & 2 & $-2 i$ & 0 & 0 & 0 & 0 & 0 & 0 \\
\hline$\left(\left(L^{\prime}\right)_{1}^{(4)}+\left(L^{\prime}\right)_{2}^{(4)}\right)$ & 4 & 0 & 0 & 0 & 0 & 0 & 0 & 0 \\
\hline
\end{tabular}

(the orbitals $\left(M_{3}^{(0)}\right)^{-}$and $\left(M_{2}^{(0)}\right)^{+}$of the projective class $K_{0}$ ) and the non-degenerate orbitals of the conduction $\pi^{*}$-bands (the orbitals $\left(M_{2}^{(0)}\right)^{+}$and $\left.\left(M_{3}^{(0)}\right)^{-}\right)$combine in pairs into doubly degenerate orbitals with the $L_{1}^{(5)}$ symmetry belonging to the projective class $K_{5}$.

In Table 10, we also present the characters of the projective representations of doubly degenerate spinor orbitals taking the electron spin into account at the point $M$. These are the orbitals $\left(\left(M^{\prime}\right)^{(1)}\right)^{+}$ and $\left(\left(M^{\prime}\right)^{(1)}\right)^{-}$. Their symmetry is characterized by the projective representations of the projective class $K_{1}$. The standard factor system for the spinor states at the point $L$ belongs to the projective class $K_{4}$ (taken from works $[1,2]$ ). All projective representations in this class, with regard for the invariance of the electronic energy states with respect to time inversion, are four-dimensional.

Table 10 also includes the characters of the projective representations of the projective class $K_{4}$ (these are the representations $P_{i}^{(4)}$, which correspond to the standard factor system of the projective class $K_{4}$ ) and the characters of the projective representations at the point $L$ in the Brillouin zone of crystalline graphite $\gamma-C$ (these are the representations $\left.L_{i}^{(4)}\right)$. The rela- tion between them is determined by formula (9) from work [2] and was also presented in Table 17 of the cited work.

From the data in Table 10, it is easy to see that the doubly degenerate spinor orbital at the point $M$ [this is the orbital $\left.\left(\left(M^{\prime}\right)^{(1)}\right)^{+}\right]$transforms into the doubly degenerate spinor orbital $\left(L^{\prime}\right)_{1}^{(4)}$ at the point $L$, and the doubly degenerate spinor orbital at the point $M$ [this is the orbital $\left(\left(M^{\prime}\right)^{(1)}\right)^{-}$] into the doubly degenerate spinor orbital $\left(L^{\prime}\right)_{2}^{(4)}$ at the point $L$. In so doing, two doubly degenerate spinor orbitals at the point $L$ [these are the orbitals $\left(L^{\prime}\right)_{1}^{(4)}$ and $\left(L^{\prime}\right)_{2}^{(4)}$, owing to the invariance of the electronic states under the time inversion at the point $L$ [1] for the valence $\pi$ - and conduction $\pi^{*}$-bands combine in pairs to form the hybridized fourfold degenerate spinor orbitals $\left(\left(L^{\prime}\right)_{1}^{(4)}+\left(L^{\prime}\right)_{2}^{(4)}\right)$.

\section{Conclusions}

The results obtained in this work allow the following conclusions to be drawn.

(i) A group-theoretic analysis has been performed for the first time for the symmetry properties of the fine structure of the electronic $\pi^{\prime}$-bands in crystalline graphite [the spatial symmetry group

ISSN 2071-0194. Ukr. J. Phys. 2020. Vol. 65, No. 7 
$\left.P 6_{3} / m m c\left(D_{6 h}^{4}\right)\right]$ and single-layer graphene [the diperiodic spatial group $P 6 / \mathrm{mmm}$ (DG80)] taking the electron spin into account. It is shown that this consideration results in a small spin-dependent splitting or a principal hybridization of electronic states, including the symmetry of the states at the intermediate points $\Delta$ and $U$ in the directions $\Gamma-\Delta-A$ and $M-U-L$, respectively, of the corresponding Brillouin zones.

(ii) The correlation between the electronic excitations in crystalline graphite taking the electron spin into account and the spinor excitations in single-layer graphene has been considered.

(iii) The principal existence of the splitting of electronic states, which arises even at insignificant energies of the spin-orbit interaction, if the electron spin is taken into account, and the principal hybridization of electronic states, at which only their degeneracy order increases, have been analyzed with the help of group-theoretic methods in detail.

1. V.O. Gubanov, A.P. Naumenko, M.M. Bilyi, I.S. Dotsenko, O.M. Navozenko, M.M. Sabov, L.A. Bulavin. Energy spectra correlation of vibrational and electronic excitations and their dispersion in graphite and graphene. Ukr. J. Phys. 63, 431 (2018).

2. V.O. Gubanov, A.P. Naumenko, M.M. Bilyi, I.S. Dotsenko, M.M. Sabov, M.S. Iakhnenko, L.A. Bulavin. Energy spectra of electron excitations in graphite and graphene and their dispersion making allowance for the electron spin and the time-reversal symmetry. Ukr. J. Phys. 65, 342 (2020).

3. M.I. Katsnelson. Graphene: Carbon in Two Dimensions (Cambridge Univ. Press, 2012) [ISBN-13: 978-0521195409; ISBN-10: 052119540].
4. E.A. Wood. The 80 diperiodic groups in three dimensions. Bell Syst. Technol. J. 43, 541 (1964).

5. E. Doni, G. Pastori Parravicini. Energy bands and optical properties of hexagonal boron nitride and graphite. Nuovo Cimento B 64, 117 (1969).

6. F. Bassani, G. Pastori Parravicini. Electronic States and Optical Transitions in Solids (Pergamon Press, 1975) [ISBN: 0080168469].

Received 16.12.19

Translated from Ukrainian by O.I. Voitenko

В.О. Губанов, А.П. Науменко,

І.С. Доченко, М.М. Сабов, Д.В. Гринъ, Л.А.Булавін

ТОНКЕ СПІНЗАЛЕЖНЕ РОЗЩЕПЛЕННЯ

ЕЛЕКТРОННИХ ЗБУДЖЕНЬ ТА ЇХНЯ ДИСПЕРСІЯ

В ОДНОШАРОВОМУ ГРАФЕНІ I ГРАФІТІ

$\mathrm{P}$ е $з$ ю м е

Досліджено дисперсійні залежності електронних збуджень одношарового графену і кристалічного графіту із врахуванням спіну електрона. Вперше визначено умови сумісності двозначних незвідних проективних представлень, що характеризують симетрію спінорних збуджень у зазначених вище структурах, та розподіли спінорних квантових станів за проективними класами та незвідними проективними представленнями для всіх точок високої симетрії у відповідних цим структурам зонах Бріллюена. Встановлено принципове існування спінзалежних розщеплень енергетичних електронних станів, зокрема, розщеплень електронних $\pi$-зон в точках Дірака, або їх принципове об'єднання. Величина спінзалежних розщеплень може бути значною, наприклад, для халькогенідів перехідних металів такої самої просторової групи симетрії, як у кристалічного графіту, але є невеликою для одношарового графену і кристалічного графіту, оскільки вона зумовлена малою енергією спін-орбітальної взаємодії для атомів вуглецю i, як наслідок, є невеликою для всіх вуглецевих структур. 